Methods A short answer questionnaire addressing these topics was completed by 131 WOTP students $(38$ girls and 93 boys).

Results The three most popular work environments were garages (tire installer, 17 boys), retail stores (stock handler, 21 boys, 9 girls) and restaurants (fast-food counter attendant and cook's helper, 17 boys, 6 girls). More than $40 \%$ of the girls are in typically female occupations: hair salon assistant (7), assistant childcare educator (5), grooming assistant (3) and recreation assistant (1). When asked if they perceived risks in their internships, $50 \%$ of girls and $80 \%$ of boys say yes. All girls say they consider OHS important or very important, while $13 \%$ of boys are indifferent or consider it not very important. Concerning the OHS training received at the workplace, $38 \%$ of the girls and $50 \%$ of the boys stated that they had received some.

Conclusion These preliminary results suggest that girls and boys are not exposed to the same environments nor the same risks. The situation seems inequitable in terms of prevention and suboptimal for all, since a large proportion reported not having an OHS training. These shortcomings should be considered in the development of new tools.

\section{RF-322 RATES OF RETURN TO WORK AND WORK ABILITY FOLLOWING KNEE REPLACEMENT}

${ }^{1}$ Elena Zaballa, Georgia Ntani, E Clare Harris, Nigel K Arden, Cyrus Cooper, Karen WalkerBone. ${ }^{1}$ University of Southampton, United Kingdom

\subsection{6/OEM-2021-EPI.393}

Introduction There is limited evidence on the ability to sustain employment following knee replacement.

Objective To describe occupational status before and after unicompartmental (UKR) and total knee replacement (TKR) and to explore work ability after both types of knee arthroplasty.

Methods This study was set within the longitudinal Clinical Outcomes in Arthroplasty study. Eligible participants were those who were aged 18-64 years at the time of their primary arthroplasty and had at least 5 years' duration followup since. All eligible participants were mailed a questionnaire which enquired about: pre- and post-operative occupations and occupational exposures; time to reach best function; and leisure-time physical activities performed postoperation. We used Cox regression to estimate crude and adjusted hazard ratios with $95 \%$ confidence intervals to explore the role of work factors in determining post-operative work ability (CI).

Results 251 useable responses were received (61\% response) amongst whom 158 (63\%) returned to any work postoperatively. Most of these, 146 (92\%) had been working pre-operatively. Detailed occupational exposure information was available for 145 (94 UKRs, 51 TKRs) of the 158 who RTW. The mean follow-up post-operation was 6.4 years $(\mathrm{SD} \pm 1)$. Adjusted models showed that workers were at increased risk of leaving their job post-operation if an average working day involved: lifting/carrying $\geq 10 \mathrm{~kg}$ (HR: 4.57 95\%CI $1.52,13.79$ ) or climbing 30 flights of stairs/day (HR:3.52 95\%CI 1.29,9.59), as compared with workers not doing these activities. Mutually adjusted models showed that it was the lifting/carrying weights in excess of $10 \mathrm{~kg}$ that was most important (HR:3.6 95\% CI 1.1,11.3).
Conclusion Many people effectively return to work post kneereplacement. However, job retention is poorer in occupations that entail lifting weights and climbing flights of stairs. Subject to replication, these findings could imply a particular role for post-UKR/TKR rehabilitation amongst people needing to RTW in physically-demanding jobs.

\section{RF-326 DOES PARTICIPATION IN MODIFIED RETURN TO WORK DIFFER FOR IMMIGRANT COMPARED TO CANADIAN- BORN WORKERS IN BRITISH COLUMBIA, CANADA?}

Sonja Senthanar, 'Mieke Koehoorn, Lillian Tamburic, Stephanie Premji, Ute Bültmann, Chris McLeod. 'University of British Columbia, Canada

\subsection{6/OEM-2021-EPI.394}

Introduction The longer workers are off work, the less likely they are to successfully return to work. Modified return-towork (MRTW) provides earlier work reintegration after an injury with the goal of full recovery and shorter work disability durations.

Objective This study examined differences in MRTW participation for immigrant compared to Canadian-born workers with a work-related injury in British Columbia.

Methods Workers' compensation claims data linked with immigration records were used to identify immigrant (economic, family or refugees/other classifications) and Canadian-born workers with an accepted short-term disability claim between 2009-2015 for acute (fracture and concussion) and chronic injuries (back strain and connective tissue). Injury cohorts were restricted to 30 days on claim for a common disability window to measure MRTW participation. The outcome of MRTW was measured as never offered MRTW or an offer of MRTW within the first 30 days on benefits. Individuals with an offer beyond 30 days were excluded.

Results In adjusted logistic regression models, immigrant classification was associated with a decreased odds ratio (OR) of receiving an offer of MRTW within 30 days across injury cohorts. For example, for workers with back strain injuries: $\mathrm{OR}=0.97$ [95\%CI $0.88,1.07]$ for economic immigrants, $\mathrm{OR}=0.72[95 \% \mathrm{CI} 0.66,0.79]$ for family class immigrants, and $\mathrm{OR}=0.74[95 \% \mathrm{CI} 0.64,0.86]$ for refugee/other classifications. Similarly, for workers with a fracture injury: $\mathrm{OR}=0.94 \quad[95 \% \mathrm{CI} \quad 0.72,1.22]$ for economic immigrants, $\mathrm{OR}=0.84 \quad[95 \% \mathrm{CI} 0.64,1.11]$ for family class immigrants, and $\mathrm{OR}=0.42 \quad[95 \% \mathrm{CI} \quad 0.24,0.76]$ for refugee/other classifications.

Conclusion Understanding why immigrant workers are less likely to be offered MRTW compared to Canadian-born workers for the same injuries is worthy of further investigation, and in particular for workers who arrived to Canada as refugees. A focus on increasing earlier provision of MRTW for longer term claims has the potential to reduce work disability duration among immigrant workers.

\section{RF-298 OCCUPATIONAL RISK OF SALMONELLOSIS AND CAMPYLOBACTERIOSIS: A NATIONWIDE POPULATION- BASED REGISTRY STUDY}

${ }^{1}$ Janneke Duijster, Lapo Mughini-Gras, Eelco Franz, Jacques Neefjes. ${ }^{1}$ National Institute for Public Health and the Environment (RIVM), Netherlands

10.1136/OEM-2021-EPI.395 